\title{
Identification of GABRA1 and $L A M A 2$ as new DNA methylation markers in colorectal cancer
}

\author{
SUNWOO LEE ${ }^{1,7}$, TAEJEONG OH ${ }^{1}$, HYUNCHEOL CHUNG ${ }^{2}$, SUNYOUNG RHA ${ }^{2}$, CHANGJIN KIM ${ }^{5}$, \\ YOUNGHO MOON ${ }^{1}$, BENJAMIN D. HOEHN ${ }^{1}$, DONGJUN JEONG ${ }^{5}$, SEUNGHOON LEE ${ }^{6}$, \\ NAMKYU KIM ${ }^{3}$, CHANHEE PARK ${ }^{2,4}$, MIAE YOO ${ }^{7}$ and SUNGWHAN AN ${ }^{1}$ \\ ${ }^{1}$ Genomictree Inc., Daejeon; ${ }^{2}$ National Biochip Research Center, ${ }^{3}$ Department of General Surgery, ${ }^{4}$ Brain Korea 21 \\ Project for Medical Sciences, College of Medicine, Yonsei University, Seoul; ${ }^{5}$ Department of Pathology, College of \\ Medicine, Soonchunhyang University, Cheonan; ${ }^{6}$ Department of Life Science, Yongin University, Yongin; ${ }^{7}$ Department \\ of Molecular Biology, College of Natural Science, Pusan National University, Pusan, Republic of Korea
}

Received August 7, 2011; Accepted October 3, 2011

DOI: 10.3892/ijo.2011.1245

\begin{abstract}
Aberrant methylation of $\mathrm{CpG}$ islands in the promoter region of genes is a common epigenetic phenomenon found in early cancers. Therefore conducting genome-scale methylation studies will enhance our understanding of the epigenetic etiology behind carcinogenesis by providing reliable biomarkers for early detection of cancer. To discover novel hypermethylated genes in colorectal cancer by genome-wide search, we first defined a subset of genes epigenetically reactivated in colon cancer cells after treatment with a demethylating agent. Next, we identified another subset of genes with relatively down-regulated expression patterns in colorectal primary tumors when compared with normal appearing-adjacent regions. Among 29 genes obtained by cross-comparison of the two gene-sets, we subsequently selected, through stepwise subtraction processes, two novel genes, GABRA1 and LAMA2, as methylation targets in colorectal cancer. For clinical validation pyrosequencing was used to assess methylation in 134 matched tissue samples from CRC patients. Aberrant methylation at target $\mathrm{CpG}$ sites in GABRA1 and LAMA2 was observed with high frequency in tumor tissues $(92.5 \%$ and $80.6 \%$, respectively), while less frequently in matched tumor-adjacent normal tissues $(33.6 \%$ for GABRA1 and $13.4 \%$ for LAMA2). Methylation levels in primary tumors were not significantly correlated with clinicopathological features including age, sex, survival and TNM
\end{abstract}

Correspondence to: Dr SungWhan An, Genomictree Inc., 829 Tamnip-dong, Yuseong-gu, Daejeon 305-510, Republic of Korea E-mail: genomictree1@korea.com

Abbreviations: GABRAl, $\gamma$-aminobutyric acid (GABA) A receptor $\alpha 1$; LAMA2, laminin $\alpha 2$ (merosin, congenital muscular dystrophy); TNM, tumor node metastasis; DAC, 5-aza-2'-deoxycytidine; ANOVA, analysis of variance; CRC, colorectal cancer; LOWESS, localized weighted regression; MtI, methylation index

Key words: colorectal cancer, methylation, genome-wide, microarray, GABRA1, LAMA2 stage. Additionally, we found that ectopic overexpression of $G A B R A 1$ in colon cancer cell lines resulted in strong inhibition of cell growth. These results suggest that two novel hypermethylated genes in colorectal cancer, GABRA1 and $L A M A 2$, may have roles in colorectal tumorigenesis and could be potential biomarkers for the screening and the detection of colorectal cancer in clinical practice.

\section{Introduction}

Colorectal cancer (CRC) is one of the most common types of neoplasia in developed countries and is the second leading cause of cancer related death $(1,2)$. The mean 5-year survival rate for $\mathrm{CRC}$ is estimated to be $<10 \%$ once metastasis occurs, but it would be greater than $90 \%$ if the cancer is found in an early stage (3). So far, digital rectal exams, fecal occult blood tests, sigmoidoscopy and colonoscopy have been used as acceptable options for early detection of CRC. But these methods lack the needed sensitivity and could be supplemented with a more sensitive and efficient screening assays using novel biomarkers. During carcinogenesis, genetic and epigenetic alterations of tumor suppressor genes are believed to play a pathogenic role $(4,5)$. Epigenetic gene silencing of tumor suppressor genes, due to hypermethylation of $\mathrm{CpG}$ islands in their promoter region, is known to frequently occur in the early stages of cancer development. Such aberrant events can be utilized as moleculardiagnostic biomarkers for early detection and risk identification in cancer patients (6).

Methylation status of p16, p14, hMLH1, TSP1, GSTP1 and $M G M T$ genes have been intensively studied in CRC (7-12). However, detection of such methylation events in known cancerassociated genes is not yet efficient enough to have clinical usability as early detection markers. Using stool-DNA, for the non-invasive early detection of CRC, studies have recently identified aberrant methylation in genes such as Vimentin, NDRG4, TFPI2 and GATA4/5 which have been shown to have a high frequency in primary tumors of CRC (13-16). The discovery of novel hypermethylated genes in tumors has stimulated renewed interest in the field. 
Development and application of several new strategies using microarray-based technology has allowed for directed, genome-wide discovery of aberrantly methylated genes (17-19). Additionally, gene expression profiling of pharmacologically reactivated genes in cancer cell lines, after demethylation by DNA methylation inhibitors, has been successfully used to discover putative genes for methylation targets in several cancers (20-22).

Therefore, to identify putative genes hypermethylated in CRC, we first performed microarray analysis after global demethylation of colon cancer cell lines. In addition, we used a second expression microarray to profile genes which showed relatively down-regulated patterns in colorectal primary tumors when compared with their normal appearing-adjacent sections. Next following methylation examinations we performed a cross-comparison of the two independent expression microarray data sets, allowing us to efficiently identify a number of putative methylation markers. For diagnostic use, we identified two novel genes, GABRA1 and LAMA2, which are epigenetically inactivated in CRC, as novel methylation markers. These markers were subsequently used for methylation assessment and verification in cell lines and clinical samples.

\section{Materials and methods}

Reagents. All chemical reagents used were purchased from Sigma-Aldrich (MA, USA) unless otherwise noted. HpaII and $M s p$ I restriction enzymes were obtained from New England Biolabs (MA, USA). Oligonucleotides were synthesized by Bioneer Inc. (Daejeon, Republic of Korea).

Cells. Human colon cancer cell lines, Caco-2 and HCT116, were purchased from the American Type Culture Collection (Manassas, VA, USA) and maintained in RPMI-1640 (JBI, Seoul, Republic of Korea) supplemented with $10 \%$ fetal bovine serum (JBI) and 100 units $/ \mathrm{ml}$ of penicillin and $100 \mu \mathrm{g} /$ $\mathrm{ml}$ of streptomycin $(\mathrm{JBI})$ in a humidified $5 \% \mathrm{CO}_{2}$ incubator at $37^{\circ} \mathrm{C}$.

Clinical specimens. Fresh-frozen primary tumors and paired tumor-adjacent normal tissues of CRC patients were obtained from Soonchunhyang University (Cheonan, Republic of Korea) and Yonsei University Medical Center (Seoul, Republic of Korea). All specimens and pertinent patient information were handled in accordance with the Institutional Review Board. Each tumor specimen was histologically verified by board-certified pathologists. Five colorectal tissue samples from cancer-free individuals were purchased from BioChain (Hayward, CA, USA).

5-aza-2'-deoxycytidine (DAC) treatment to cell lines. Colon cancer cell lines were plated at the concentration of $1 \times 10^{6}$ cells on $100 \mathrm{~mm}$ dishes and treated with $5 \mu \mathrm{mol} / \mathrm{l}$ of DAC for five days. The medium was changed every $24 \mathrm{~h}$ after treatment in order to maintain the concentration of DAC at a constant level. For control, cells were treated with an equivalent volume of $50 \%$ acetic acid. On day 6, cells were harvested and their genomic DNA and total RNA were extracted with Trizol reagent (Invitrogen, Carlsbad, CA, USA) according to the manufacturer's instructions.
Gene expression analysis. Human 17K cDNA microarrays (Genomictree, Daejeon, Republic of Korea) containing 17,075 samples of human cDNA, which represents 15,724 different genes (Research Genetics, Huntsville, AL, USA), were manufactured as previously described (23) and used in gene expression analysis. The synthesis of the target cDNA probes and the hybridization were performed according to the process previously described (23). Briefly, each $50 \mu \mathrm{g}$ of total RNA was mixed with $2 \mu \mathrm{g}$ of oligo(dT) (24) (GenoTech, Daejeon, Republic of Korea) in $15.4 \mu \mathrm{l}$ of RNase-free water and incubated at $65^{\circ} \mathrm{C}$ for $10 \mathrm{~min}$. After that, single-stranded cDNA was synthesized in the presence of Cy3-dUTP or Cy5-dUTP ( $1 \mathrm{mM}$ each, NEN Life Science Products, Boston, MA, USA) at $42^{\circ} \mathrm{C}$ for $2 \mathrm{~h}$. Total RNA from the match-paired colorectal tissues and from the common reference RNA pools of the eleven cancer cell lines (23) were labeled with Cy5 and Cy3, respectively. Both Cy5 and Cy3-labeled cDNA were purified using a PCR purification kit (Qiagen, Hilden, Germany) and were hybridized onto human $17 \mathrm{~K}$ cDNA microarrays. The arrays were incubated at $42^{\circ} \mathrm{C}$ for $16 \mathrm{~h}$ in the humidified hybridization chamber (Genomictree).

Microarray data analysis. The hybridized microarrays were imaged by using an Axon 4000B scanner (Molecular Devices, Synnyvale, CA, USA). The signals and the background fluorescence intensities were calculated for each probe by averaging the intensities of every pixel inside the probe spot region using GenePix Pro 4.0 software (Molecular Devices). Spots of poor quality or indistinguishable signal level from the background were excluded. Data normalization and the selection of differentially-expressed genes were performed using GeneSpring 7.3.1 (Agilent Technologies, Palo Alto, CA, USA).

To analyze differentially-expressed genes between tumor and paired tumor-adjacent normal tissue in colorectal tissues samples, the 'Cross gene error model for replicates' was activated. Gene expression data were normalized in two ways: 'LOWESS' and 'per gene normalization'. In 'per gene normalization', the data from a given gene were normalized to the median expression level of the gene across all samples. The data sets were then assigned into two groups (paired tumor-adjacent tissues and tumor tissues). The expression profiles of the two groups were compared using ANOVA tests (with variances that were not equal, $\mathrm{p}<0.01$ ) to identify genes that were differentiallyexpressed between them.

To determine reactivation of genes by DAC, gene expression data was normalized using LOWESS. In the analysis of DAC-treated Caco-2 cell compared with control the cut-off value of 2-fold and higher was selected for genes to be considered reactivated. The raw DNA microarray data were submitted to the Gene Expression Omnibus (http://www.ncbi.nlm.nih. gov/ geo/) with the following accession number: GSE26799.

HpaII-MspI-PCR assay. The promoter and the 5'-untranslated region (UTR) of the selected genes (3 kb: -2.0-1.0 kb from the transcription start site) were scanned for $\mathrm{CpG}$ islands using the MethPrimer program (http://itsa.ucsf.edu/ urolab/methprimer/ index 1.html); primers were designed for the HpaII-MspI-PCR assay $(24,25)$. To avoid incomplete digestion, $400 \mathrm{ng}$ of genomic DNA was digested with excessive units of HpaII and MspI (80 units each) for $6 \mathrm{~h}$ at $37^{\circ} \mathrm{C}$ with enzyme buffers recommended by the suppliers and purified using a PCR purification 
Table I. Primers and PCR conditions for HpaII-MspI-PCR assay (upper), primers and PCR conditions for pyrosequencing analysis (middle) and RT-PCR (lower). ${ }^{\mathrm{a}}$

\begin{tabular}{|c|c|c|c|c|}
\hline Gene & $\begin{array}{c}\text { Forward } \\
\text { primer }\left(5^{\prime} \rightarrow 3^{\prime}\right)\end{array}$ & $\begin{array}{c}\text { Reverse } \\
\operatorname{primer}\left(5^{\prime} \rightarrow 3^{\prime}\right)\end{array}$ & $\begin{array}{c}\text { Annealing } \\
\text { temperature }\left({ }^{\circ} \mathrm{C}\right)\end{array}$ & $\begin{array}{l}\text { Amplicon } \\
\text { size (bp) }\end{array}$ \\
\hline$F G F R 3$ & CAGGTCAGTCAACGCAGCCTCT & GCAGGCCTGTGTTTGCATAGC & 58 & 271 \\
\hline GABRAl & AGGAGCACGCAGAGTCCATGAT & TACCTAAGGCCCCCTCTGGACA & 55 & 168 \\
\hline ID3 & GCCTGCACTCTCCCTCAAAGC & CCACTCAAGGACCCAGGACAGA & 58 & 269 \\
\hline LAMA2 & CCTAGCTGTTTGCATTTCCCAG & CCACTTCTCGGGAGCCAGAG & 55 & 304 \\
\hline MTAl & CAGAGCATTTCTGCCAGGGGTA & AGGCCCACCTGACCAACCTCTA & 58 & 252 \\
\hline$M T 1 G$ & CGCTCAAGGGACCTTGCACTT & GTTCCCAAGCGAGAAGGGAAGA & 55 & 208 \\
\hline$R G S 2$ & AAGCCGAGGCCTCATAAATGCT & CGGAGAGGGAAGAAAGCCATA & 55 & 209 \\
\hline SLC6A8 & GCCTGCACTCTCCСТCAAAGC & CCACTCAAGGACCCAGGACAGA & 58 & 202 \\
\hline
\end{tabular}

\begin{tabular}{|c|c|c|c|c|c|c|}
\hline \multirow{2}{*}{$\begin{array}{l}\text { Gene } \\
A M A 2\end{array}$} & \multirow[b]{2}{*}{ Forward primer } & \multirow{2}{*}{$\begin{array}{c}\text { Sequences }\left(5^{\prime} \rightarrow 3^{\prime}\right) \\
\text { TTATAAGTTAAGGTTAGGGATAG }\end{array}$} & \multicolumn{4}{|c|}{ PCR conditions } \\
\hline & & & $\begin{array}{l}94^{\circ} \mathrm{C} \\
(3 \mathrm{~min})\end{array}$ & $\begin{array}{l}94^{\circ} \mathrm{C} 30 \mathrm{sec} \\
58^{\circ} \mathrm{C} 30 \mathrm{sec}\end{array}$ & 45 cycles & $\begin{array}{l}72^{\circ} \mathrm{C} \\
(5 \mathrm{~min})\end{array}$ \\
\hline & Reverse primer & Biotin-AAAATACAACCCAAACCCATAC & & $72^{\circ} \mathrm{C} 30 \mathrm{sec}$ & & \\
\hline & Sequencing primer $(\mathrm{F})$ & TAAGTTAAGGTTAGGGGATA & & & & \\
\hline \multirow[t]{3}{*}{ GABRAl } & Forward primer & GGGAAGTAAATTTGGGTGTGAA & $\begin{array}{l}94^{\circ} \mathrm{C} \\
(3 \mathrm{~min})\end{array}$ & $\begin{array}{l}94^{\circ} \mathrm{C} 30 \mathrm{sec} \\
58^{\circ} \mathrm{C} 30 \mathrm{sec}\end{array}$ & 45 cycles & $\begin{array}{l}72^{\circ} \mathrm{C} \\
(5 \mathrm{~min})\end{array}$ \\
\hline & Reverse primer & Biotin-CCCCCTCTAAACACAAAATCTCTT & & $72^{\circ} \mathrm{C} 30 \mathrm{sec}$ & & \\
\hline & Sequencing primer $(\mathrm{F})$ & ATTAAGTGAGTGAGAGGTAG & & & & \\
\hline \multirow[t]{2}{*}{ LAMA2 } & Forward primer & TGGGCATGATACAGGTTGAA & $\begin{array}{l}95^{\circ} \mathrm{C} \\
(3 \mathrm{~min})\end{array}$ & $\begin{array}{l}95^{\circ} \mathrm{C} 15 \mathrm{sec} \\
55^{\circ} \mathrm{C} 30 \mathrm{sec}\end{array}$ & 40 cycles & $\begin{array}{l}72^{\circ} \mathrm{C} \\
(5 \mathrm{~min})\end{array}$ \\
\hline & Reverse primer & TGACCCTGTGTTTGTTGGAG & & $72^{\circ} \mathrm{C} 30 \mathrm{sec}$ & & \\
\hline \multirow[t]{2}{*}{ GABRAl } & Forward primer & AAGCTCTGGAATTGTTGAAT & $\begin{array}{l}95^{\circ} \mathrm{C} \\
(3 \mathrm{~min})\end{array}$ & $\begin{array}{l}95^{\circ} \mathrm{C} 15 \mathrm{sec} \\
55^{\circ} \mathrm{C} 30 \mathrm{sec}\end{array}$ & 40 cycles & $\begin{array}{l}72^{\circ} \mathrm{C} \\
(5 \mathrm{~min})\end{array}$ \\
\hline & Reverse primer & CAACAGCTAAGTGCAGTGAT & & $72^{\circ} \mathrm{C} 30 \mathrm{sec}$ & & \\
\hline
\end{tabular}

${ }^{\mathrm{a}} G A B R A 1$ and $L A M A 2$ primers for real-time PCR are identical with those of RT-PCR.

kit (Qiagen). The sequences of the gene-specific primer sets used are shown in Table I. For PCR, 20 ng of digested genomic DNA was used as a template in a $25-\mu 1$ reaction mixture containing 2.5 U of Taq DNA polymerase (Intron BioTech, Republic of Korea), 2.5 pmoles of each primer and $0.2 \mathrm{mM}$ of each dNTP in PCR buffer $(10 \mathrm{mM}$ Tris- $\mathrm{HCl}$ at $\mathrm{pH} 7.5,50 \mathrm{mM}$ $\mathrm{KCl}, 1.5 \mathrm{mM} \mathrm{MgCl}$, $1 \mathrm{mM}$ DTT, $10 \mathrm{mM}$ 2-mercaptoethanol). The thermal cycling parameters were optimized for each amplicon. To assess PCR adequacy, the human interferon-2 gene without HpaII site was used as a control. The PCR products from uncut, HpaII-digested and MspI-digested DNA were separated on a $1.5 \%$-agarose gel stained with ethidium bromide and visualized by UV illumination. The band intensity was measured with the Scion image program (Scion Corporation, Maryland, USA). The target region was considered to be methylated if the band intensity of the HpaII amplicon was 2-fold greater than that of the $M s p I$ amplicon; otherwise, the sample was considered to be unmethylated.

Quantitative real-time PCR. Relative gene expression levels of clinical samples were quantified by using the LightCycler system (7900 HT, Applied Biosystems, Foster city, CA, USA), and SYBR Green I dye (Roche Diagnostics, GmbH, Germany).
Real-time PCR and monitoring was performed according to the manufacturer's instructions. Briefly, RNA samples isolated from cell lines and clinical samples were reverse-transcribed, and the expression was quantitated by real-time PCR and normalized by $\beta$-actin gene expression. Primer sequences and cycling parameters for GABRA1 and LAMA2 genes are shown in Table I. Real-time PCR was repeated three times to verify the results, and the mean mRNA expression was used for subsequent analysis.

Quantitative bisulfite-pyrosequencing analysis. The target 5'-UTR region of GABRA1 and the promoter region of LAMA2 were amplified using the forward primer and the biotinylated reverse primer designed by PSQ Assay Design (Biotage AB, Uppsala, Sweden) (Table I). Genomic DNA (200 ng) was modified by sodium bisulfite using the EZ DNA methylation kit (Zymo Research, Irvine, CA, USA) according to the manufacturer's instructions. Bisulfite-modified DNA was amplified in a $25-\mu 1$ reaction volume with the primer set and 5 units of Taq polymerase (Solgent, Inc., Daejeon, Republic of Korea), as described in Table I. The PCR products were visualized on a $1.5 \%$-agarose gel by ethidium bromide staining for PCR verification. Pyrosequencing reactions were performed with 
sequencing primers (Table I) on the PSQ HS 96A System (Biotage AB) according to the manufacturer's instructions. The methylation index (MtI) of each gene promoter, and of each sample, was calculated as the average value of ${ }^{\mathrm{m}} C /\left({ }^{\mathrm{m}} C+C\right)$ for all examined $\mathrm{CpGs}$ in the target region. Methylation positivity was artificially calculated and considered as valid when the MtI of the tumor was higher than that of the paired tumor-adjacent normal tissue. A statistical relationship between MtI and the clinicopathological features of tumor samples was calculated by using the MedCalc program (http://www.medcalc.be).

Construction of mammalian GABRA1-expression vector and cell viability assay. A full-length cDNA clone for GABRAI (hMU002273) was provided by the 21C Frontier Human GeneBank (Korea Research Institute of Bioscience and Biotechnology, Daejeon, Republic of Korea). Full-length cDNA (3,440 bp) from the GABRAl gene (GenBank Accession no. BC030696) was amplified with sequence specific primers; 5'-ATT AGA ATT CGC GAT GAG GAA AAG T-3' for forward and 5'-TAA TCT CGA GGA TCT ATT GAT GTG GTG-3' for reverse, and subcloned into the EcoRI/XhoI site of pcDNA4 ${ }^{\mathrm{TM}} /$ HisMax vector (Invitrogen).

HCT116 cells $\left(3 \times 10^{3}\right)$ were plated in to each well of a 96-well plate, incubated for $24 \mathrm{~h}$, followed by transfection with 0.5 or $0.75 \mu \mathrm{g} / \mathrm{ml}$ of $G A B R A 1$-expressing plasmids using Fugene HD transfection reagent (Roche Applied Science, Mannheim, Germany). A pcDNA4 ${ }^{\mathrm{TM}} /$ HisMax vector was transfected as a control. After $48 \mathrm{~h}$ of incubation, transfectants were treated with WST-1 reagent (Roche Applied Science), according to the manufacturer's instructions. The cell viability was assayed with an ELISA reader (Benchmark Plus Microplate Spectrophotometer, Bio-Rad, Hercules, USA) at $440 \mathrm{~nm}$.

\section{Results}

Identification of candidate methylation target genes by expression microarrays. The flowchart for step-wise screening is summarized in Fig. 1. First, Caco-2 cells were treated with DAC then screened for gene reactivation using expression microarray analysis. A total of 1,379 genes were found to be reactivated $\geq 2.0$-fold in the DAC-treated cells when compared to untreated cells.

Second, we performed expression microarray analysis on primary colorectal tumors and match-paired tissues from five CRC patients. This allowed us to obtain a group of genes that demonstrated down-regulation in tumor tissues when compared to adjacent normal tissues. From this group, 238 genes were found to be statistically significant (ANOVA, $\mathrm{p}<0.01)$ for down-regulation in tumors. Next, we chose a subset of 29 genes in total from both groups which overlapped as candidates for methylation target genes. This selection was based on the assumption that gene expression is relatively suppressed in tumor cells due to aberrant methylation in their regulatory regions (Table II).

Out of 29 genes, 11 were excluded because they did not harbor $\mathrm{CpG}$ islands in the 5 regulatory region by in silico analysis. Therefore, 18 candidate genes were subjected to methylation assessment in two cell lines using HpaIIMspI-PCR assay. We observed that 8 out of 18 candidate genes were methylated in at least one cell line.

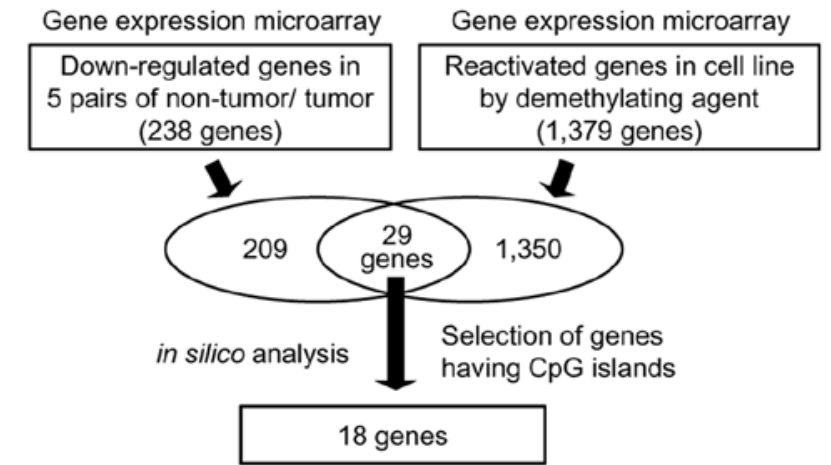

Methylation assay by enzyme digestion and PCR

Confirmation for methylation in cell line

8 genes

Methylation assay by enzyme digestion and PCR

Tissue verification with 5 normals and 36 pairs of clinical tissues

GABRA1, LAMA2

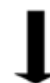

Further clinical validation

Figure 1. Diagram of systematic approach for discovering CRC-specific hypermethylated target genes. First, two sets of genes were identified via expression microarray analysis (1,379 and 238 genes that were reactivated with DAC treatment in Caco-2 cell and down-regulated in tumors, respectively). Twenty-nine genes were selected by cross-comparison of the gene sets from the microarray experiments. Through a further stepwise filtering process, GABRAl and $L A M A 2$ genes were finally selected as novel hypermethylated candidates in CRC. Numbers in each box represent the actual number of genes that meet each of the selection criteria.

Verification of eight candidate genes by HpaII-MspI-PCR assay in clinical samples. For verification, we used HpaIIMspI-PCR assay to determine the methylation status of 8 genes in primary tumors and matched adjacent normal tissues from 36 CRC patients, including the 5 samples used in the microarray analysis and the 5 normal tissues from healthy individuals. The methylation patterns of the 8 genes in the clinical samples were subdivided into 3 groups (Fig. 2). The first group, including $S L C 6 A 8, M T 1 G$ and FGFR3 showed no specificity due to its high frequency of methylation in all samples and even in normal tissues. Although completely unmethylated in normal tissues, the third group containing RGS2, MTAI and ID3, showed a lower frequency of methylation in both tumor and matched adjacent normal tissues. Only the second group genes, GABRA1 and LAMA2, showed a relatively high frequency of methylation in primary colorectal tumors $(44.4 \%$ and $72.2 \%$, respectively) with a lower frequency in adjacent normal tissues. Furthermore, we could not detect any methylation of these genes in normal tissues (Fig. 2). Therefore, we selected GABRAl and $L A M A 2$ for further clinical validation due to their potential in discriminating tumor from normal tissue with relatively higher sensitivity and specificity.

Clinical validation of DNA hypermethylation of GABRAI and LAMA 2 by quantitative pyrosequencing analysis. HpaII$M s p$ I-PCR assay provides only qualitative information of methylation status at the site recognized by restriction enzyme 
Table II. Twenty-nine candidate genes identified by cross-comparison between two sets of gene expression microarray analysis.

Gene Description $\quad \begin{gathered}\text { Systematic Hypermethylation Loss-of-function } \\ \text { number }\end{gathered}$ Refs.

ABCB1 ATP-binding cassette, sub-family B (MDR/TAP), AA455911 Breast cancer
member 1
AKR1B10 Aldo-keto reductase family 1, member B10 (aldose reductase)

AOC3 Amine oxidase, copper containing 3 (vascular adhesion protein 1)

AI924753

AA036975

Colorectal cancer

CA12 Carbonic anhydrase XII

AA171613

CA2 Carbonic anhydrase II

$\mathrm{H} 23187$

CFHL1 Complement factor H-related 1 pseudogene

AA703392

DPT Dermatopontin

R48303

DSIPI TSC22 domain family, member 3

AA775091

Uterine leiomyoma

ETV2 Ets variant gene 2

AA 885210

FGFR3 Fibroblast growth factor receptor 3

AA419620 Lung cancer

GABRA1 Gamma-aminobutyric acid (GABA) A receptor $\alpha 1$

AA776176

HPGD Hydroxyprostaglandin dehydrogenase 15-(NAD)

AA775223

ID3 Inhibitor of DNA binding 3, dominant negative

AA482119 helix-loop-helix protein

KIAA0931 PH domain and leucine rich repeat protein

AA417700

Colorectal cancer phosphatase-like

LAMA2 Laminin, $\alpha 2$ (merosin, congenital muscular dystrophy)

AA034939

LGALS2 Lectin, galactoside-binding, soluble 2 (galectin 2) AA872397

LMO2 LIM domain only 2 (rhombotin-like 1)

AA280651

MGLL Monoglyceride lipase

T60135

MT1B Metallothionein 1B (functional)

H72723

MTIG Metallothionein $1 \mathrm{G}$

H53340

MTA1 Metastasis associated 1

N71159

PXMP2 Peroxisomal membrane protein 2, $22 \mathrm{kDa}$

N70714

$R G S 2 \quad$ Regulator of G-protein signaling 2, $24 \mathrm{kDa}$

AI675670

Hepatocellular carcinoma

Tongue squamous cell carcinoma
Helicobacter-induced gastric cancer

AA486082

Colorectal cancer

Colon carcinoma

$S G K \quad$ Serum/glucocorticoid regulated kinase

AA292226

SLC6A8

Solute carrier family 6 (neurotransmitter transporter, creatine), member 8

AA676836

SMPDL3A Sphingomyelin phosphodiesterase, acid-like 3A

AA451851

Prostate cancer

THEA

Acyl-CoA thioesterase 11

AA862436

TM4SF2 Tetraspanin 7

N93505

Glioblastoma 


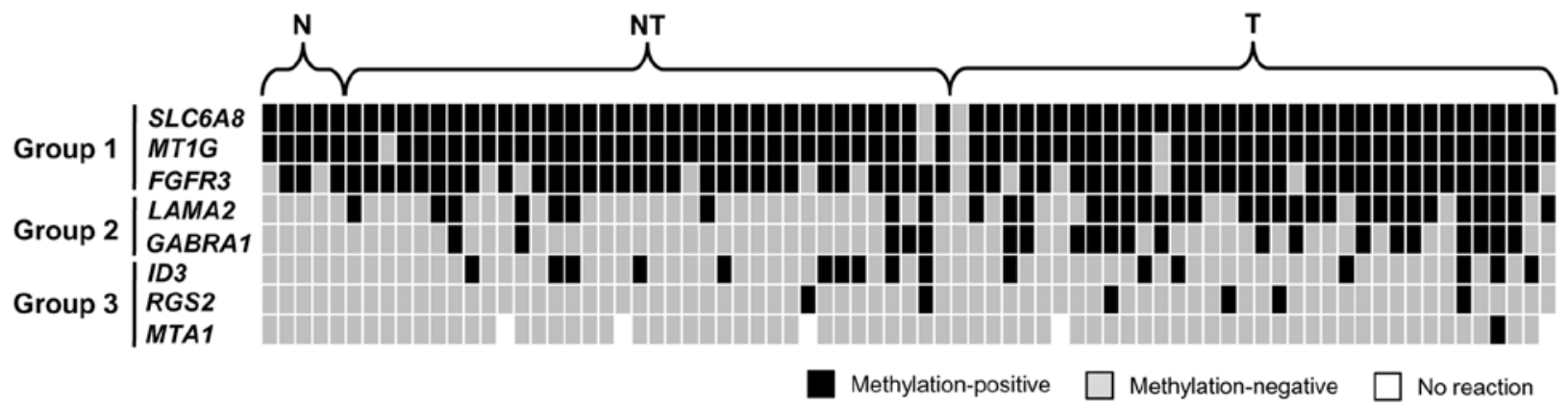

Figure 2. Methylation status of eight candidate genes by HpaII-MspI-PCR assay. Methylation status in individual tumors (T), paired tumor-adjacent normals (NT) from 36 colon cancer patients and normal tissues $(\mathrm{N})$ from five non-patients was analyzed. Black, grey and white pixels represent methylation-positive, methylation-negative and PCR failed, respectively.
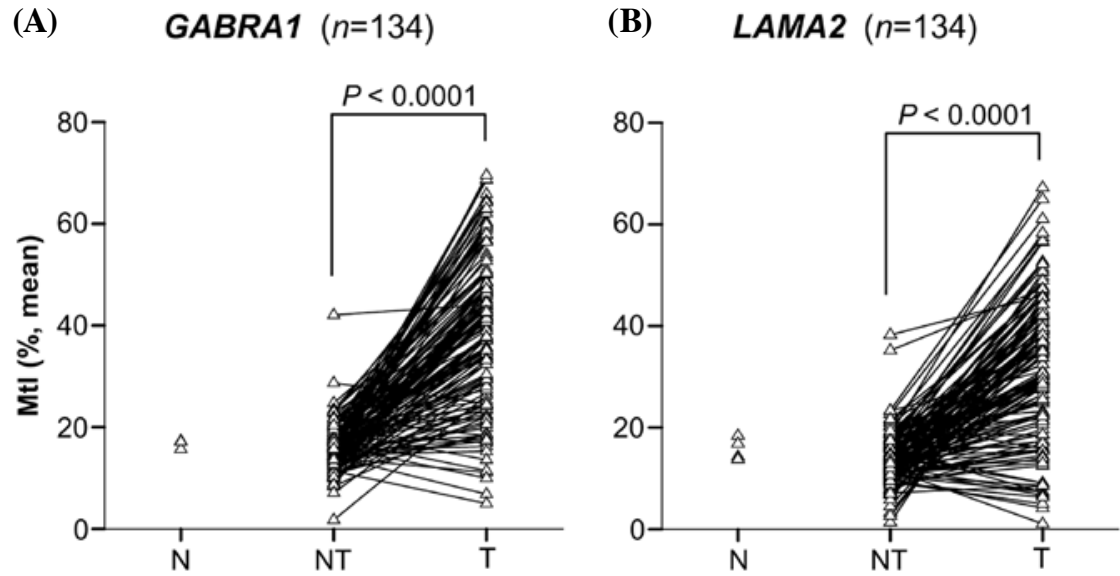

Figure 3. Quantitative analysis of hypermethylation of GABRA1 and LAMA2 in tissues from 134 colorectal cancer patients. Multiple line/scatter plots of MtIs for GABRA1 (A) and LAMA2 (B) were plotted with results from pyrosequencing analysis of 134 clinical tumor tissue samples (T) and 134 paired tumor-adjacent tissue samples $(\mathrm{NT})$ and 4 normal tissues $(\mathrm{N})$. The samples from the same patient are linked with a straight line ( $\leq 0.05)$. P-values were calculated with chi-square test.

in a given specimen. To overcome this limitation we applied a pyrosequencing-based quantitative methylation assay to estimate not only the presence of methylation but also the level of methylation fraction of GABRA1 and LAMA2. This assay confirmed that each CpG site in target regions of GABRAl and LAMA2 had acquired high levels of aberrant methylation in Caco-2 and HCT116 cell lines (Fig. 4C). We then assessed the level of methylation fraction of two genes in 134 primary tumor and match-paired adjacent normal tissues from CRC patients representing various clinical features (diagnosis parameters, Table III) and normal tissues from disease-free individuals $(\mathrm{n}=4)$. Methylation levels of GABRAI and LAMA2 were estimated to range from $5.0 \%$ to $69.6 \%$ and from $1.1 \%$ to $67.2 \%$, respectively, in tumor tissues (T) and from $1.8 \%$ to $42.1 \%$ and from $1.3 \%$ to $38.2 \%$, respectively, in tumor-adjacent normal (NT) tissues while from $15.9 \%$ to $17.3 \%$ and $13.9 \%$ to $18.4 \%$ in normal tissues (N) (Fig. 3).

Normal samples demonstrated the GABRA1 and LAMA2 highest MtI values as $17.53 \%$ and $18.25 \%$, respectively. These values were used as the thresholds of each gene to determine hypermethylation positivity. We also observed in primary tumor tissues samples a higher frequency of hypermethylation in both genes (92.5\% for GABRAl and $80.6 \%$ for LAMA2), while less in adjacent normal tissues (33.6\% for GABRAl and $13.4 \%$ for LAMA2) (Table IV).
Table III. Clinicopathological data of 134 CRC patients.

\begin{tabular}{lc}
\hline Variable & No. of patients $(\mathrm{n}=134)$ \\
\hline Age & $60.7 \pm 10.1$ \\
Gender & \\
Male & 82 \\
Female & 52 \\
Site & \\
Colon & 64 \\
Rectum & 70 \\
Histological grade & \\
Well & \\
Moderately & 24 \\
Poorly & 102 \\
TNM stage & 8 \\
I & \\
II & 28 \\
III & 39 \\
IV & 51 \\
\hline
\end{tabular}


(A)

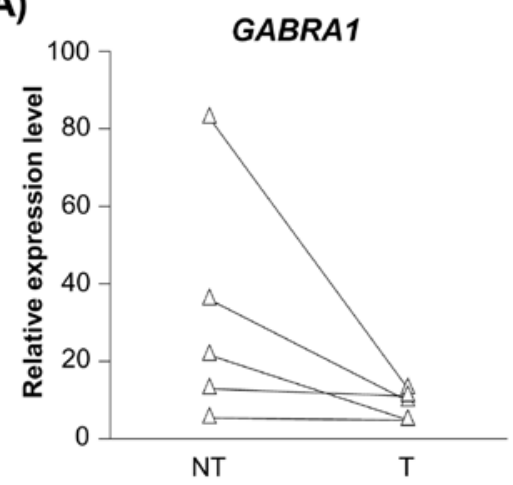

LAMA2

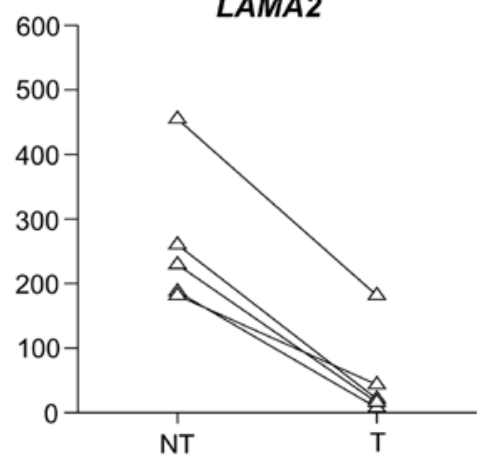

(B)

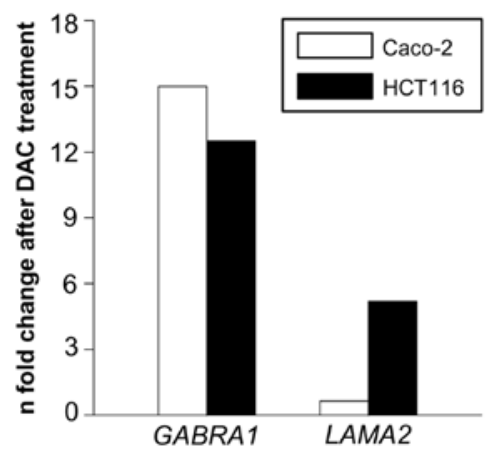

(C)

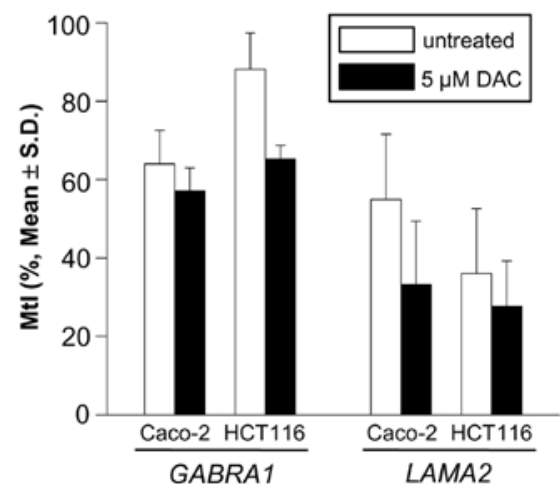

Figure 4. Epigenetic silencing of GABRA1 and $L A M A 2$ in colon cancer cells and tissues. (A), Comparison of expression levels for GABRA1 and $L A M A 2$ in the five colorectal tumor tissues with paired tumor-adjacent normal tissues using real-time PCR. (B), Restoration of down-regulated GABRA1 and $L A M A 2$ mRNA levels by DAC treatment. Total RNAs isolated from DAC-treated Caco-2 (open bar) and HCT116 (closed bar) were reverse-transcribed, and GABRA1 and $L A M A 2$ mRNA expression levels were quantified using real-time PCR. Expression levels were normalized with $\beta$-actin gene expression and fold changes of each gene expression were calculated relating to corresponding untreated cell lines. (C), MtIs of GABRA1 and LAMA2 in DAC-treated Caco-2 and HCT116 cells were measured using pyrosequencing analysis. Open bar, untreated cells; closed bar, DAC-treated cells.

Table IV. Methylation index and frequency of hypermethylation of GABRAI and LAMA2 in 134 pairs of colorectal tissues.

\begin{tabular}{|c|c|c|c|c|c|}
\hline \multirow[b]{2}{*}{ Gene } & \multicolumn{2}{|c|}{$\begin{array}{l}\text { Methylation index } \\
(\%, \text { mean } \pm \mathrm{SD})^{\mathrm{a}}\end{array}$} & \multicolumn{3}{|c|}{$\begin{array}{l}\text { Frequency of hypermethylation-positive } \\
\text { (no. of cases, \%) }\end{array}$} \\
\hline & $\begin{array}{l}\text { Paired tumor- } \\
\text { adjacent tissues }\end{array}$ & $\begin{array}{l}\text { Tumor } \\
\text { tissues }\end{array}$ & Normal & $\begin{array}{l}\text { Paired tumor- } \\
\text { adjacent tissues }\end{array}$ & $\begin{array}{l}\text { Tumor } \\
\text { tissues }\end{array}$ \\
\hline$G A B R A 1(\mathrm{n}=134)$ & $16.00 \pm 4.59$ & $38.84 \pm 15.04$ & $0 / 4(0)$ & 45/134 (33.6) & $124 / 134(92.5)$ \\
\hline LAMA2 $(\mathrm{n}=134)$ & $13.64 \pm 5.03$ & $31.61 \pm 13.94$ & $0 / 4(0)$ & $18 / 134(13.4)$ & $108 / 134(80.6)$ \\
\hline Vimentin $(\mathrm{n}=55)$ & $12.79 \pm 10.04$ & $43.42 \pm 22.76$ & $0 / 4(0)$ & $19 / 55 \quad(34.5)$ & $49 / 55 \quad(89.1)$ \\
\hline
\end{tabular}

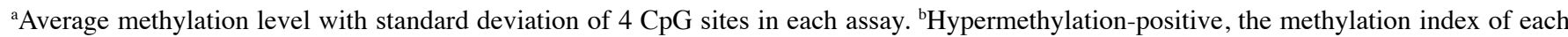
gene greater than the corresponding cut-off values of each gene. Each cut-off value was determined as the highest MtIs of each gene in 4 normal samples (GABRA1, 17.53; LAMA2, 18.25; Vimentin, 12.85).

We evaluated the association of clinical parameters with methylation levels of GABRA1 and LAMA2 genes in 134 CRC patients. There was no significant association between methylation levels and several clinicopathological parameters including age, tumor node metastasis (TNM) stage, gender and survival (Table V).

Verification of epigenetic regulation of GABRA1 and LAMA2 $m R N A$ expression. First, we evaluated the relative expression level of GABRA1 and LAMA2 mRNA in 5 pairs of tumor and tumor-adjacent normal tissue used in the expression microarray through application of real-time PCR. Expression levels of both GABRA1 and LAMA2 were relatively lower in all of the 5 tumor samples compared to those of the matched tumor-adjacent normal tissues, as predicted by the expression microarray analysis (Fig. 4A).

In order to confirm that GABRA1 and LAMA2 are transcriptionally suppressed by aberrant DNA methylation, we investigated pharmacological reactivation of regulatory regions in Caco-2 and HCT116 cells following DAC treatment. We 
Table V. The relationship between clinicopathological parameters and MtIs of GABRAI and LAMA2.

\begin{tabular}{|c|c|c|}
\hline \multirow[b]{2}{*}{ Features } & \multicolumn{2}{|c|}{$\operatorname{MtIs}(\%, \text { mean } \pm \mathrm{SD})^{\mathrm{a}}$} \\
\hline & $G A B R A 1$ & LAMA2 \\
\hline \multicolumn{3}{|l|}{ Gender } \\
\hline Male $(n=82)$ & $39.1 \pm 14.4$ & $30.5 \pm 14.1$ \\
\hline Female $(n=52)$ & $38.5 \pm 16.3$ & $33.3 \pm 13.8$ \\
\hline p-value ${ }^{b}$ & 0.869 & 0.216 \\
\hline \multicolumn{3}{|l|}{ Age } \\
\hline$\leq 65(n=82)$ & $37.9 \pm 15.5$ & $29.9 \pm 12.9$ \\
\hline$\geq 65(n=52)$ & $40.4 \pm 14.5$ & $34.4 \pm 15.9$ \\
\hline p-value ${ }^{b}$ & 0.336 & 0.085 \\
\hline \multicolumn{3}{|l|}{ Survival } \\
\hline Survival $(n=106)$ & $38.7 \pm 14.8$ & $32.2 \pm 13.6$ \\
\hline Death $(n=28)$ & $39.6 \pm 16.5$ & $29.5 \pm 15.4$ \\
\hline p-value ${ }^{b}$ & 0.783 & 0.368 \\
\hline \multicolumn{3}{|l|}{ TNM stage } \\
\hline $\mathrm{I}, \mathrm{II}(\mathrm{n}=67)$ & $38.5 \pm 16.3$ & $33.3 \pm 13.8$ \\
\hline III, IV (n=67) & $39.1 \pm 14.4$ & $30.5 \pm 14.1$ \\
\hline p-value ${ }^{b}$ & 0.514 & 0.275 \\
\hline
\end{tabular}

${ }^{\mathrm{a}}$ Methylation levels (MtIs) represent the average of MtIs of each $\mathrm{CpG}$ site with standard deviation (SD). ${ }^{\mathrm{b}} \mathrm{p}$-values were calculated with the use of the Kruskal-Wallis test ( $\mathrm{p} \leq 0.05)$.

observed that reactivation of GABRAI and $L A M A 2$ genes was induced by DAC treatment (Fig. 4B). Furthermore, pyrosequencing assessment revealed a slight decrease of the DNA methylation level in the DAC-treated cells compared to the untreated cells: GABRAI (54.9\% vs. $64.0 \%$ in Caco-2 and $65.3 \%$ vs. $88.2 \%$ in HCT116), LAMA2 (33.2\% vs. $57.1 \%$ in Caco-2 and $27.7 \%$ vs. $36.0 \%$ in HCT116) (Fig. 4C).

Inhibition of cell growth in colon cancer cells by ectopic expression of GABRA1. To examine whether ectopic expression of GABRAl can inhibit colorectal cancer cell lines, we transfected GABRAl-expressing mammalian vector or an empty vector into HCT116 cells, in which expression of GABRAl is suppressed by promoter methylation. After $48 \mathrm{~h}$ of incubation, three independent cell viability assays consistently showed a significant growth inhibition of GABRAl-transfected cells in a concentration-dependent manner (Fig. 5).

\section{Discussion}

To identify new CRC specific methylation sites in the human genome, which can be utilized as biomarkers for early detection of colorectal cancer, we employed microarray based expression analyses following the concept that down-regulation of gene activity is at least partly attributed to promoter hypermethylation in CRC cells. It is well-recognized in cancer cell lines that hypermethylation in a subset of promoter genes can lead to transcriptional silencing. Additionally, these corresponding genes

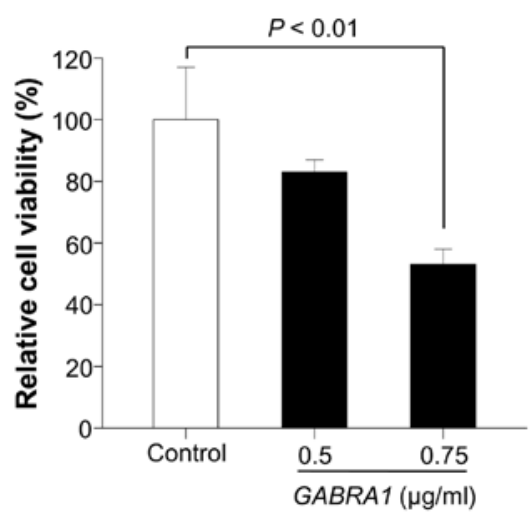

Figure 5. Cell growth inhibition by ectopic expression of GABRA1. GABRA1expressing mammalian plasmid was transiently transfected into HCT116 cells. After $48 \mathrm{~h}$ of incubation, cell viability of cells transfected with pcDNA/ HisMax, $0.5 \mu \mathrm{g} / \mathrm{ml}$ or $0.75 \mu \mathrm{g} / \mathrm{ml}$ of pcDNA/GABRAl was assayed with WST-1 reagent and normalized values were plotted $(n=3, p \leq 0.05)$. Each of the experimental values was normalized with a control (pcDNA/HisMax) value.

can be characterized by reactivation following treatment with demethylating agents $(4,20,26)$. Recent studies by Suzuki and Ogawa et al have used pharmacological reactivation to screen for methylation candidate genes in CRC cell lines $(20,21)$. However, when we carried out similar experiments using gene expression microarrays, we found such an approach to be less efficient for selection of tumor-specific methylated genes. We hypothesize reactivated genes in the cell line, following treatment with demethylating agents, are composed not only of tumor-specifically methylated genes but also of tissue-specific or tissue culture-specific methylated genes. In this study we sought to increase the sensitivity and specificity of detecting genes that are related to promoter hypermethylation and clinically relevant in CRC. Thus, we developed a refined stepwise screening system to achieve our goals. First, we added an additional set of microarray analysis to obtain a group of genes which are specifically down-regulated in tumors when compared to paired adjacent normal tissues. We then cross-compared both expression microarray data sets to select overlapping genes based on the assumption that they are down-regulated in tumor tissues due to promoter methylation. Through a stepwise filtering procedure (Fig. 1) we have identified two genes, GABRAI and LAMA2 as methylation markers specific for CRC.

Recently several new genes such as TFPI2, NDRG4, GATA4/5 and Vimentin have been identified as promising methylation markers in stool DNA test for the early detection of CRC (13-16). Notably, all of them showed a high frequency of aberrant methylation in primary tumor tissues of CRC patients. Glöckner et al identified TFPI2 as a new marker which revealed a remarkable frequency of aberrant methylation in all CRC adenomas $(97 \%, \mathrm{n}=56)$ and in stages I-IV $(99 \%, \mathrm{n}=115)(14)$. The prevalence of NDRG4 promoter methylation was $70 \%(\mathrm{n}=83)$ and $86 \%(n=184)$ in two independent sets of primary tumors compared with $4 \%(\mathrm{n}=48)$ in non-cancerous colon mucosa $(15)$. The transcription factors GATA4 and GATA5 also evaluated as potential biomarkers were observed in $70 \%(\mathrm{n}=90)$ and $79 \%$ $(n=77)$, respectively, of CRC while $6 \%(n=88)$ and $13 \%(n=100)$, respectively in normal tissues from non-cancerous controls (16). Vimentin exon-1 sequence has been intensively studied for its use as a marker in stool DNA testing. Chen et al observed in their 
earlier studies that this gene was highly methylated in tumors from two independently collected groups of CRC patients, $83 \%$ $(\mathrm{n}=46)$ and $53 \%(\mathrm{n}=107)(13)$. In more recent studies, Zou et al detected Vimentin methylation in $72 \%$ of cancers $(n=74), 84 \%$ of adenoma $(n=62)$ and $11 \%$ of normal epithelia $(n=70)(27)$. In our study, for inter-study comparison, we quantitatively assessed Vimentin methylation status by pyrosequencing in 55 out of 134 randomly selected CRC samples. This demonstrated a comparable frequency of hypermethylation positivity $(89.1 \%$, 49/55, Table IV), indicating a good match between our and other clinical samples. From these clinical samples, we observed high methylation frequencies in GABRA1 and LAMA2, 92.5\% and $80.6 \%$, respectively (Table IV) demonstrating the prevalence of aberrant methylation in these genes is comparable to those of all genes mentioned above in primary tumors of CRC patients.

Additionally, we found that a small portion of patients demonstrated hypermethylation positivity in at least one gene in adjacent normal tissues (33.6\% for GABRAI and $13.4 \%$ for LAMA2, $\mathrm{n}=134$, Table IV). We speculate that even if tumor-adjacent normal tissue is histologically normal, but has undergone abnormal epigenetic processes, such as aberrant gene promoter methylation as a field-defect (28) suggest that GABRA1 and LAMA2 genes acquired aberrant methylation at an early stage of colorectal tumorigenesis. However, it is possible that aberrant methylation in adjacent normal tissues can be attributed to tumor cell micro-invasion. Further, we report that methylation level and frequency of GABRAl and LAMA2 genes in primary tumors was irrespective of clinicopathological features including cancer stage, even though the methylation positivity of both genes were similar across all stages of CRC (Table V). We believe that this combination of data strongly supports our findings on early markers with high sensitivity and specificity in detecting CRC in patients before clinical symptoms or pathology is present. Thus, further studies are warranted to evaluate this potential clinical application.

It has been reported that $G A B R A 1$, a subunit of $\gamma$-aminobutyric acid receptor $\left(\mathrm{GABA}_{\mathrm{A}} \mathrm{R}\right)$, is directly repressed by c-myc oncoprotein, which plays a critical role in the regulation of cellular proliferation and apoptosis, and that overexpression of this gene leads to the induction of apoptosis (29). Also, it has been reported that the deletion of GABRAI locus is involved in the intraurothelial phases of bladder neoplasia (30). Laminins also play key roles in normal and neoplastic tissues, including cell adhesion and migration, cell proliferation, differentiation, and cell shape (31). $\alpha 2$ is a subunit of laminin-2 (merosin) and laminin-4 (S-merosin), and capillaries expressing the laminin $\alpha 2$ chain in basement membranes may be considered as early developing vessels in normal and neoplastic human tissues.

In this study, we were able to demonstrate that ectopic overexpression of GABRAl in colon cancer cell lines did result in strong inhibition of cell growth and proliferation (Fig. 5). Unfortunately, we were unable to investigate the function of LAMA2 in colon cancer cells due to technical difficulties in cloning. In order to fully investigate the role of $G A B R A 1$ and $L A M A 2$ in tumor suppression, other tests such as soft agar colony formation, mobility/invasion assays and, ideally in vivo studies should be conducted, but are currently outside the scope of this study.
We do not clearly know at what point aberrant methylation events occur and what are the molecular mechanisms behind DNA methylation during tumorigenesis. It would be benificial to identify new gene methylation targets to be used as markers for early cancer detection. In order to obtain such optimal targets, a continued effort in identifying new genes with a high frequency of aberrant methylation in cancer patients and early stages of tumorigenesis is needed. The combination of expression microarray analysis in cell lines and clinical tissues confers a powerful advantage in selection of candidate hypermethylated genes for targets.

In this study, we discovered two novel hypermethylated genes in colorectal cancer, GABRA1 and LAMA2, by combining two subsets of genes selected from pharmacologically reactivated genes in colon cancer cell lines and genes down-regulated in colorectal primary tumors. Here, we demonstrate for the first time that the regulatory regions of GABRA1 and LAMA2 are frequently hypermethylated in colorectal cancers. These two genes are potential biomarkers for the screening and the detection of colorectal cancer in clinical practice.

\section{Acknowledgements}

This work was supported by a grant for the National Biochip Center (Project no. 0405-BC01-0604-002) from Ministry of Health and Welfare, Republic of Korea. We thank Mr. C. Yoon, vice president of Genomictree, Inc. for manufacturing $17 \mathrm{~K}$ cDNA microarray and Benjamin Hoehn, Biolingual, Inc. for editing and proofreading the manuscript.

\section{References}

1. McHugh SM, O'Donnell J and Gillen P: Genomic and oncoproteomic advances in detection and treatment of colorectal cancer. World J Surg Oncol 7: 36, 2009.

2. Jemal A, Tiwari RC, Murray T, et al: American Cancer Society: Cancer Statistics. CA Cancer J Clin 54: 8-29, 2004.

3. Dashwood RH: Early detection and prevention of colorectal cancer (Review). Oncol Rep 6: 277-281, 1999.

4. Jones PA and Baylin SB: The fundamental role of epigenetic events in cancer. Nat Rev Genet 3: 415-428, 2002.

5. Feinberg AP: Cancer epigenetics takes center stage. Proc Natl Acad Sci USA 98: 392-394, 2001.

6. Laird PW: The power and the promise of DNA methylation markers. Nat Rev Cancer 3: 253-266, 2003.

7. Zou HZ, Yu BM, Wang ZW, et al: Detection of aberrant p16 methylation in the serum of colorectal cancer patients. Clin Cancer Res 8: 188-191, 2002.

8. Sato F, Harpaz N, Shibata D, et al: Hypermethylation of the p14 (ARF) gene in ulcerative colitis-associated colorectal carcinogenesis. Cancer Res 15: 1148-1151, 2002.

9. Herman JG, Umar A, Polyak K, et al: Incidence and functional consequences of hMLH1 promoter hypermethylation in colorectal carcinoma. Proc Natl Acad Sci USA 95: 6870-6875, 1998.

10. Rojas A, Meherem S, Kim YH, Washington MK, Willis JE, Markowitz SD and Grady WM: The aberrant methylation of TSP1 suppresses TGF-betal activation in colorectal cancer. Int J Cancer 123: 14-21, 2008.

11. Kim HC, Roh SA, Ga IH, Kim JS, Yu CS and Kim JC: CpG island methylation as an early event during adenoma progression in carcinogenesis of sporadic colorectal cancer. J Gastroenterol Hepatol 20: 1920-1926, 2005.

12. Nagasaka T, Sharp GB, Notohara K, et al: Hypermethylation of $\mathrm{O}^{6}$-methylguanine-DNA methyltransferase promoter may predict nonrecurrence after chemotherapy in colorectal cancer cases. Clin Cancer Res 9: 5306-5312, 2003.

13. Chen WD, Han ZJ, Skoletsky J, et al: Detection in fecal DNA of colon cancer-specific methylation of the nonexpressed vimentin gene. J Natl Cancer Inst 97: 1124-1132, 2005. 
14. Glöckner SC, Dhir M, Yi JM, et al: Methylation of TFPI2 in stool DNA: a potential novel biomarker for the detection of colorectal cancer. Cancer Res 69: 4691-4699, 2009.

15. Melotte V, Lentjes MH, van den Bosch SM, et al: N-Myc downstream-regulated gene 4 (NDRG4): a candidate tumor suppressor gene and potential biomarker for colorectal cancer. J Natl Cancer Inst 101: 916-927, 2009.

16. Hellebrekers DM, Lentjes MH, van den Bosch SM, et al: GATA4 and GATA5 are potential tumor suppressors and biomarkers in colorectal cancer. Clin Cancer Res 15: 3990-3997, 2009.

17. Toyota M, Ho C, Ahuja N, et al: Identification of differentially methylated sequences in colorectal cancer by methylated $\mathrm{CpG}$ island amplification. Cancer Res 59: 2307-2312, 1999.

18. Gebhard C, Schwarzfischer L, Pham TH, Schilling E, Klug M, Andreesen R and Rehli M: Genome-wide profiling of CpG methylation identifies novel targets of aberrant hypermethylation in myeloid leukemia. Cancer Res 66: 6118-6128, 2006.

19. Hahn MA and Pfeifer GP: Methods for genomic-wide analysis of DNA methylation in intestinal tumors (Review). Mutat Res 693: 77-83, 2009.

20. Suzuki H, Gabrielson E, Chen W, et al: A genomic screen for genes upregulated by demethylation and histone deacetylase inhibition in human colorectal cancer. Nat Genet 31: 141-149, 2002.

21. Ogawa K, Utsunomiya T, Mimori K, et al: Genomic screens for genes upregulated by demethylation in colorectal cancer: possible usefulness for clinical application. Int J Oncol 27: 417-426, 2005

22. Cameron EE, Bachman KE, Myohanen S, Herman JG and Baylin SB: Synergy of demethylation and histone deacetylase inhibition in the re-expression of genes silenced in cancer. Nat Genet 21: 103-107, 1999.

23. Yang SH, Kim JS, Oh TJ, et al: Genome-scale analysis of resveratrol-induced gene expression profile in human ovarian cancer cells using a cDNA microarray. Int J Oncol 22: 741-750, 2003.

24. Yang IV, Chen E, Hasseman JP, et al: Within the fold: assessing differential expression measures and reproducibility in microarray assays. Genome Biol 3(11): research0062.1-0062.12, 2003.

25. Singer-Sam J, Le Bon JM, Tanguay RL and Riggs AD: A quantitative HpaII-PCR assay to measure methylation of DNA from a small number of cells. Nucleic Acids Res 18: 687, 1990

26. Yamashita S, Tsujino Y, Moriguchi K, Tatematsu M and Ushijima T: Chemical genomic screening for methylation silenced genes in gastric cancer cell lines using 5-aza-2'-deoxycytidine treatment and oligonucleotide microarray. Cancer Sci 97: 64-71, 2006.

27. Zou H, Harrington JJ, Shire AM, et al: Highly methylated genes in colorectal neoplasia: implications for screening. Cancer Epidemiol Biomarkers Prev 16: 2686-2696, 2007.

28. Shen L, Kondo Y, Rosner GL, et al: MGMT promoter methylation and field defect in sporadic colorectal cancer. J Natl Cancer Inst 97: 1330-1338, 2005

29. Vaknin UA and Hann SR: The alpha1 subunit of GABAA receptor is repressed by c-myc and is pro-apoptotic. J Cell Biochem 97: 1094-1103, 2006.
30. Kram A, Li L, Zhang RD, et al: Mapping and genome sequence analysis of chromosome 5 regions involved in bladder cancer progression. Lab Invest 81: 1039-1048, 2001.

31. Patarroyo M, Tryggvason $\mathrm{K}$ and Virtanen I: Laminin isoforms in tumor invasion, angiogenesis and metastasis. Semin Cancer Biol 12: 197-207, 2002.

32. Muggerud AA, Rönneberg JA, Wärnberg F, et al: Frequent aberrant DNA methylation of ABCB1, FOXC1, PPP2R2B and PTEN in ductal carcinoma in situ and early invasive breast cancer. Breast Cancer Res 12: R3, 2010.

33. Toiyama Y, Miki C, Inoue Y, Kawamoto A and Kusunoki M: Circulating form of human vascular adhesion protein-1 (VAP-1): decreased serum levels in progression of colorectal cancer and predictive marker of lymphatic and hepatic metastasis. J Surg Oncol 99: 368-372, 2009

34. Catherino WH, Leppert PC, Stenmark MH, Payson M, PotlogNahari C, Nieman LK and Segars JH: Reduced dermatopontin expression is a molecular link between uterine leiomyomas and keloids. Genes Chromosomes Cancer 40: 204-217, 2004

35. Cortese R, Hartmann O, Berlin K and Eckhardt F: Correlative gene expression and DNA methylation profiling in lung development nominate new biomarkers in lung cancer. Int $\mathbf{J}$ Biochem Cell Biol 40: 1494-1508, 2008

36. Ye H, Yu T, Temam S, et al: Transcriptomic dissection of tongue squamous cell carcinoma. BMC Genomics 9: 69, 2008.

37. Liu J, Weiss HL, Rychahou P, Jackson LN, Evers BM and Gao T: Loss of PHLPP expression in colon cancer: role in proliferation and tumorigenesis. Oncogene 28: 994-1004, 2009.

38. Takaishi S and Wang TC: Gene expression profiling in a mouse model of Helicobacter-induced gastric cancer. Cancer Sci 98 : 284-293, 2007.

39. Kanda M, Nomoto S, Okamura Y, et al: Detection of metallothionein $1 \mathrm{G}$ as a methylated tumor suppressor gene in human hepatocellular carcinoma using a novel method of double combination array analysis. Int J Oncol 35: 477-483, 2009.

40. Lauer C, Völkl A, Riedl S, Fahimi HD and Beier K: Impairment of peroxisomal biogenesis in human colon carcinoma. Carcinogenesis 20: 985-989, 1999.

41. Jiang Z, Wang Z, Xu Y, Wang B, Huang W and Cai S: Analysis of RGS2 expression and prognostic significance in stage II and III colorectal cancer. Biosci Rep 30: 383-390, 2010.

42. Rauhala HE, Porkka KP, Tolonen TT, Martikainen PM, Tammela TLJ and Visakorpi T: Dual-specificity phosphatase 1 and serum/glucocorticoid-regulated kinase are downregulated in prostate cancer. Int J Cancer 117: 738-745, 2005.

43. Liu JW, Nagpal JK, Sun W, et al: ssDNA-binding protein 2 is frequently hypermethylated and suppresses cell growth in human prostate cancer. Clin Cancer Res 14: 3754-3760, 2008

44. Yokota T, Kouno J, Adachi K, et al: Identification of histological markers for malignant glioma by genome-wide expression analysis: dynein, alpha-PIX and sorcin. Acta Neuropathol 111: 29-38, 2006. 